\title{
A REVIEW OF DENTAL IMPLANT PROBLEMS AND REMEDIES
}

\author{
Jayant P. Morey ${ }^{1}$, Abhijeet A. Raut ${ }^{2}$, Ashish Bodhade ${ }^{3}$ \\ ${ }^{I}$ Departement of Mechanical Engineering, GHRCE, Rashtrasant Tukadoji Maharaj Nagpur University, \\ ${ }^{2}$ Assistant Professor at Department of Mechanical Engineering, GHRCE, Nagpur, MH, India. \\ ${ }^{3}$ Associate Professor V.S.P.M's Dental College and Research Centre, Nagpur, MH, India.
}

\begin{abstract}
The purpose of this study is to shows the usefulness of dental implant. In this paper include different types of abutments, tier system and structure which is used in dental implant. In this study shows the types of connections of abutments. There are various types of stresses which reason to diseases related dental implant. Forces act initially on the neck of dental implant. There are many types of abutments which are used for fixation of crown. The main objective is to perform analysis of failure on dental implant and post. The more focus of this study on abutment. Objective is to provide alternative solution to overcome on failure due to infection, diseases which are comes after implant. This paper includes diseases.

Failures of dental implants are frequently clinical problems. So there is need of analysis of abutment in dental implant is essential. Purpose of this study is analysis and process which used for evaluation of abutment and implant.
\end{abstract}

Key words:- Dental implant, stresses, abutment connection, Evaluation -_***

\section{INTRODUCTION}

Artificial teeth which is used to replace and support to real teeth is known as a dental implant. Dental implant is an fabricated supporter which fill the space of reel teeth. There are various types of lengths and diameters used in implant fixtures. There are crown, abutment, abutment screw and implant which make completed to dental implant. Dental implant fix where there is teeth is loss due to age, accident, diseases, etc.It is surgically implanted into the jaw bone.Abutment and implant can be attached. Attachments are available in number of design. Crown is the tooth which fixed into theJaw bone with the help of implant. The root is the part of the tooth that is effectively replaced by an implant. The abutment is fixed by an abutment screw in implant, which is mechanically screwed then crown is fixed on to the abutment.

\section{Structure of dental implant:-}

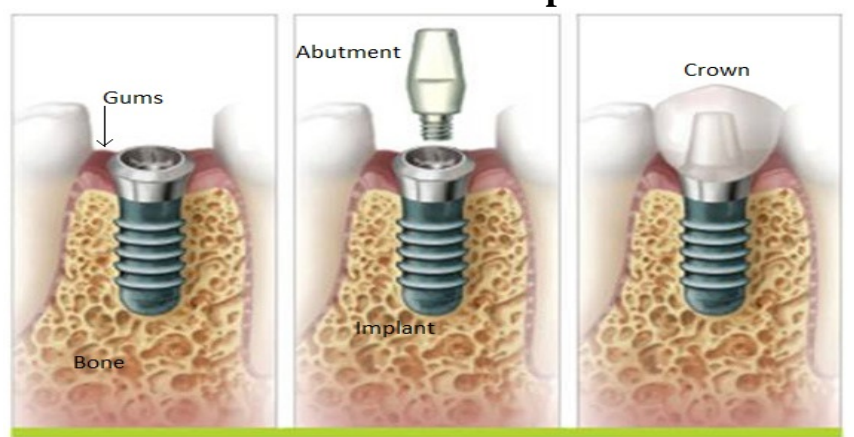

Fig 1.

In the bone, dental implant fixed surgically and the abutment screwd interally into implant which help to fix crown. After fixation of implant and abutment with the help cement crown placed on abutment. In this way dental implant placed which completed the need of reel teeth. Figure shows the basic process of dental implant fixation.
Tier of dental implant:-

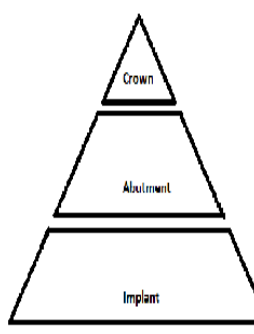

Three tier system
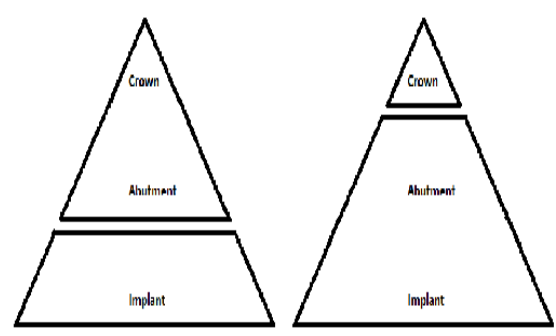

Two tier system
A dental implant with three tier system includes three individual parts like crown, abutment and implant. A dental implant with two tier systems includes two individual parts like crown and abutment form a single part and the implant is a separate part or opposite of that abutment and implant makes a single part and crown is individual in dental implant system. Figure shows separate form about tier system of dental implant.

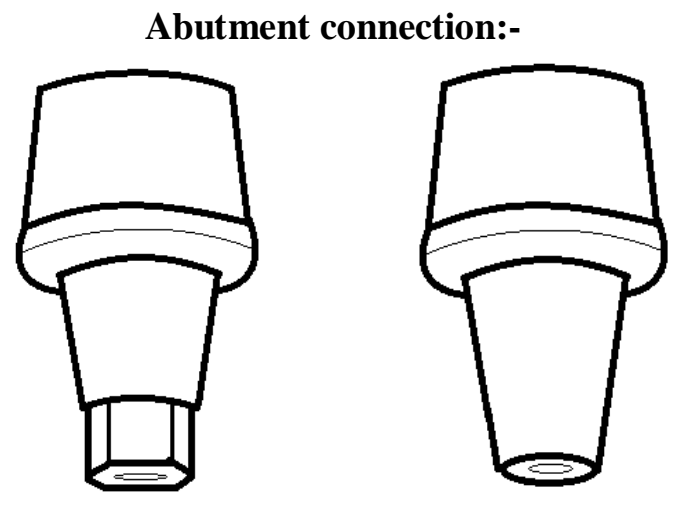

Internal hexagonal

Internal conical

Fig 3. 
Micro motion is at lower portion of internal hexagonal abutments if we compared to internal conical abutment. In internal hexagonal connection stresses occur so there is increase the chances of failure of dental implant. Edges are present in internal hexagonal design at the connection of abutment. In between implant and abutment these edges are used to fix.

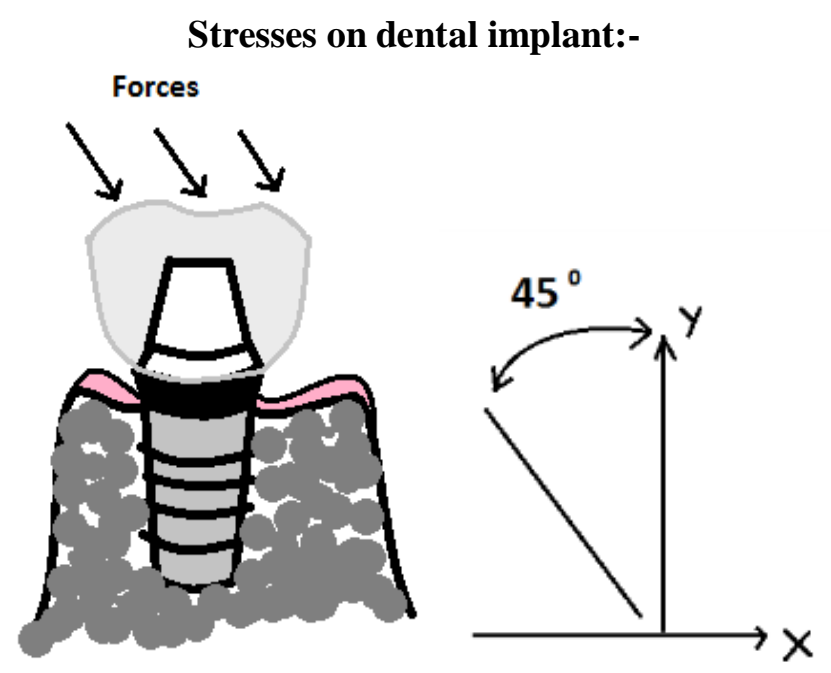

Fig 4.

Stress distribution in the bone around an implant under vertical load and combined load of vertical angle of $45^{\circ}$ is investigate.

External Hex implant-abutment used. The implant-abutment complex was fixed in bone and subjected to load of $200,500,1000 \mathrm{~N}$ vertically and in angle of $45^{\circ}$ of Masticatory force were used..

\section{Problem Statement:-}

Study the existing dental implant design and find out the failure due to the stress, diseases in those design. Select solution for drawback which comes due to the stress.

\section{Optimization process}

The crown is made to be fixed directly to the implant by cement. The abutment provides the retention and support to dental implant body.

Availability of a maximum number of parts or components of implant body is increases the dentist confusion at the selection process of parts. The method of classification of appropriate abutments for implant body is focused. The tier system for selection of dental implant is provided. This provide the understanding of the best available options of parts or components of implant for the treatment of patients.[1]

If microgap is find in the dental implant and bone after fixed it may cause the disease around dental implant. It is an initial stage of diseases and due to micro gap peri-implant hard and soft tissue leads to bone loss and implant failure. There is micro motion at the lower positionof internal hexagonal abutments. Internal hexagonal connection leads to produce stress of dental implant so it is increases the possibilities to be failure dental implant. TheEdges in abutment is used to connect the abutment and implant. Over the abutment crown fixed. These abutment edges are used to fix in system and abutment classified into two types which are the conical type and internal hexagonal type of abutment.

Micro gap leads to the infection of tissue due its damage gums and it may cause to the future failure of dental implant. Internal hexagonal connections helps to lock abutment to the implant and it increase the retention. Reduce the gap is increase the durability of implant.[2]

Stress are generally occur at the neck of the implant as well as around the implant body. When the thickness is reduced, stresses are increase in external thread of dental implant. Masticatory force is found on implant. The stresses changes asdifferent implant thicknesses increases of various diameters. An implant body system includes of an crown, abutment, abutment screw and implant.

The process of assembly is includes screwing the implant in the bone. First implant fixed into the bone then abutment placed into implant. After that crown is fixed on the abutment.[3]

According to clinical and animal studies bone loss around the implants that may cause to implant failures.

Diameter of implant body, implant shape, length of dental implant,and abutment type is not the only reason for bone loss.

External hex implant body abutment generated the maximum stress under vertical loading condition of forces.Internal Hex generated less as compare to the external. Bone quality like spongy bone define more stress.[4]

Micro gap between abutment and implant can leads to problems such as peri-implantitis and fatigue failures. This study consist the value of microgap of external and internal connections. The abutment and implant is affected due to the masticatory force by means of chewing and biting force. There is comparison between the abutment and implant and micro gaps for the two piece kind of abutments as external hexagon joints means external connection and as hexagon antirotational device means internal connection. To find the level of stress at which the sample supported.

Cases of failure find due to the abutment screw loosening and later fracture. The internal connection had a smaller microgap than the external connection. Gap leads to disease which may leads to implant fail.[5]

Evaluation of effect of taper on retention in straight and angled implant in abutment The retention of straight abutments in implant was more as compared to angled abutment. Using angled abutment, permanent join be the choice for cementation in the implant.

The force required for tensile failureness of straight abutments is 54.9 (4.14 standard deviation ) and in the use of angled abutment was 39.0 . 
In preangled abutments with angulation varying from $15^{\circ}$ to $35^{\circ}$ is commercially available. It can be concluded that straight abutments had more bond strength as compared to angled abutment in dental implant. In straight abutments, provical can be used to join and for angled abutment the cement selected.[6]

In different bone qualities with angled and straight abutments,comparison of stress distribution around an dental implant is investigate. In three dimensional finite element modelwith angled and straight abutment of the premaxilla region and $4 \mathrm{~mm}, 3 \mathrm{~mm}, 9 \mathrm{~mm}, 10 \mathrm{~mm}$ dimensions of dental implant process were done.

For study an operation done with different bone qualities. A load which is known as static load is applied on each abutment as $178 \mathrm{~N}$.

Around the dental implantvalues of Von Misses stress were found. Ifthe angle of abutment change then distribution of stresses also changed. In the study found that Von Misses stress found more in straight kind of abutment if the bone quality has changed. In angled abutments high stresses induced.[7]

In the study found that the peri-implantitis and

Peri-implant mucositis kind of bacteria which is leads to fail the dental implants. These

Studies also focused on the bacteria which is the reason for loose of dental implant in jaw bone.If periodontal disease found then it sign of dental implant is at the risk for failure. Failing or loose thedental implant found because of periimplant disease, peri-implant mucositis, and the peri-implantitis

Peri-implant diseases

Peri-implant mucositis:-

Around the dental implant the soft tissues surrounded.

Peri- implantitis:-

There is an loss of bone which is supported around an dental implant.[8]

\section{CONCLUSION}

From the review of research paper it is concluded that proper implant design is needed to increase durability of implant. The combination of sharp thread and narrow cross section might be delete for fatigue resistance in dental implant. Solution for implant failure is need to find impeccable design of Dental Implant.

\section{REFERENCES}

[1]. Sanjay Karunagaran, B.D.S., D.D.S., M.S.D., Gregory J. Paprocki, D.D.S.,Russell Wicks, D.D.S., M.S., Sony Markose, B.D.S., D.D.S., M.S.D., A Review of Implant Abutments - Abutment Classification to Aid Prosthetic Selection, Journal of the Tennessee Dental Association / pubmed.gov US National Library of MedicineNational Institutes of Health. [2].Saidin Syafiqah,Mohammed Rafiq Abdul Kadir, Eshamsul Sulaiman,Norhayaty Abu Kassim, Finite Element Analysis on Internal Hexagonaland Internal Conical
Abutment, 2010 IEEE EMBS Conference on Biomedical Engineering \& Sciences (IECBES 2010), Malaysia,

[3] R.C.Van Staden, H. Guan \& Y.C. Loo

N.W. Johnson ,N. Meredith, Stress distribution characteristics in dental implant influenced by its wallThickness, online article.

[4]. Siddharth Shelat, BS Kularashmi, H Annapoorani, R Chakravarthy,

Effect of two different abutment types on stress distribution in the bone around an implant under two loading conditions, Journal of Dental Implants Jul - Dec 2011 - Vol 1 - Issue 2 [5]. F. J. Gil M. Herrero-Climent - P. Lazar J. V. Rios29 o, Implant- abutment connections: influence of the design on the micro gap and their fatigue and fracture behavior of dental implants, December 2013 Accepted: 28 March 2014 Springer Science Business Media NewYork 2014 [6].Roseline Meshramkar, Aishwarya Nayak, Abhishek Kavlekar, Ramesh K Nadiger, K Lekha,A study to evaluate the effect of taper on retention of straight and angled implant abutment,Journal of Dental Implants - Jan - Jun

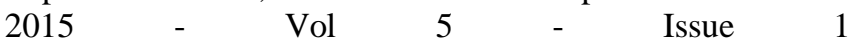
[7]. Arun Kumar, G.B. Mahesh, Dadu George, Three Dimensional Finite Element Analysis of Stress Distribution Around Implant with Straight and Angled Abutments in Different

Bone Qualities, The Journal of Indian Prosthodontic Society, 2013

[8].Ana Paula Martini, Amı'lcar Chagas Freitas Jr, Eduardo Passos Rocha, Erika Oliveira de Almeida, Rodolfo Bruniera Anchieta, Sidney Kina, and Guilherme Bortolon Fasolo,Straight and Angulated Abutments in Platform Switching: Influence of Loading on Bone Stress by ThreeDimensional Finite Element Analysis

,The Journal of Craniofacial Surgery \& Volume 23, Number 2, $\quad$ March 2012

[9]Aravind Buddula Bacteria and dental implants: A review Journal of Dental Implants - Jan - Jun 2013 - Vol 3 - Issue 1 